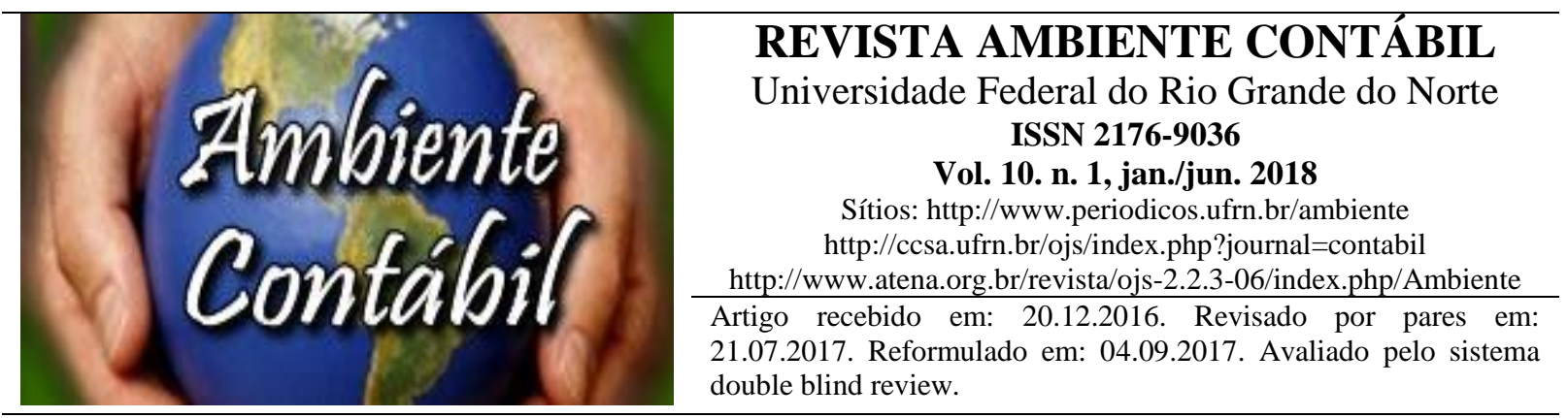

\title{
EFEITOS DA CONVERGÊNCIA ÀS NORMAS CONTÁBEIS INTERNACIONAIS NA RELEVÂNCIA DA INFORMAÇÃO CONTÁBIL DE EMPRESAS BRASILEIRAS
}

EFFECTS OF CONVERGENCE ON INTERNATIONAL ACCOUNTING STANDARDS ON THE RELEVANCE OF ACCOUNTING INFORMATION OF BRAZILIAN COMPANIES

\section{EFECTOS DE LA CONVERGENCIA CON LAS NORMAS INTERNACIONALES DE CONTABILIDAD EN LA RELEVANCIA DE EMPRESAS INFORMACIÓN DE CONTABILIDAD BRASILEÑAS}

Autores

\begin{abstract}
Alini da Silva
Doutoranda em Ciências Contábeis e Administração na Universidade Regional de Blumenau FURB. Endereço: Secretaria do Programa de Pós-Graduação em Ciências Contábeis, PPGCC sala D-202 - Campus I, Universidade Regional de Blumenau, Rua Antônio da Veiga, 140 Bairro Itoupava Seca, CEP 89030-903 - Blumenau-SC. Brasil - Telefone: (47) 3321-0565 Identificadores (ID):

Lattes: http://lattes.cnpq.br/0860389773926033

Research Gate: https://www.researchgate.net/profile/Alini_Da_Silva3 Google Citations: https://scholar.google.com.br/citations?user=jJLCzpkAAAAJ\&hl=pt-BR

E-mail: alinicont@gmail.com
\end{abstract}

Josiane Brighenti Mestra em Ciências Contábeis na Universidade Regional de Blumenau - FURB. Contadora da

Empresa Tona Holding de Participações Ltda (TONA). Endereço: Secretaria do Programa de Pós-Graduação em Ciências Contábeis, PPGCC sala D-202 - Campus I, Universidade Regional de Blumenau, Rua Antônio da Veiga, 140 - Bairro Itoupava Seca, CEP 89030-903 Blumenau-

SC. Brasil. Telefone: (47) 3321-0565. Identificadores (ID): Lattes: http://lattes.cnpq.br/3567833646042438

E-mail: josianebrighenti@gmail.com

Roberto Carlos Klann Doutor em Ciências Contábeis e Administração pela Universidade Regional de Blumenau FURB. Coordenador e Professor no Programa de Pós-Graduação em Ciências Contábeis na 
Universidade Regional de Blumenau - FURB. Endereço: Secretaria do Programa de PósGraduação em Ciências Contábeis, PPGCC sala D-202 - Campus I, Universidade Regional de Blumenau, Rua Antônio da Veiga, 140 - Bairro Itoupava Seca, CEP 89030-903 Blumenau-SC.

Brasil. Telefone: (47) 3321-0565.

Identificadores (ID):

Lattes: http://lattes.cnpq.br/8538571735256993

Research Gate: https://www.researchgate.net/profile/Roberto_Klann

E-mail: rklann@furb.br

\begin{abstract}
RESUMO
As normas internacionais de contabilidade podem apresentar incremento informacional às demonstrações financeiras, quando as normas contábeis anteriormente aplicadas, apresentarem qualidade inferior as IFRS. A relevância da informação contábil é uma característica qualidade das demonstrações, a qual evidencia a relação das informações com o preço das ações. Deste modo, o objetivo deste estudo consistiu em verificar a influência do processo de convergência às normas contábeis internacionais do IASB na relevância da informação contábil divulgada por empresas brasileiras. A amostra refere-se a 274 empresas de capital aberto, que dispunham de todas as informações para a realização do estudo na base de dados Economática ${ }^{\circledR}$. O período de análise compreendeu os anos de 2006 a 2013. A pesquisa caracteriza-se como descritiva, documental e quantitativa. Para a análise dos dados utilizou-se de dados em painel, por meio do software STATA. Os resultados indicaram que o valor patrimonial da ação, o lucro por ação e o retorno anual da ação no período pós-convergência apresentaram incremento informacional, mostrando-se mais alinhados com o preço das ações. Deste modo, infere-se que as IFRS agregaram relevância às informações contábeis divulgadas, contribuindo com a qualidade da informação contábil.

Palavras-chave: Convergência contábil. IFRS. Empresas brasileiras. Relevância da informação.
\end{abstract}

\begin{abstract}
International accounting standards may present an informational increase to the financial statements, when the accounting standards previously applied, present a lower quality than IFRS. The relevance of the accounting information is a characteristic quality of the statements, which shows the relation of the information with the stock price. Therefore, the objective of this study was to verify the influence of the convergence process on IASB international accounting standards on the relevance of the accounting information disclosed by Brazilian companies. The sample refers to 274 publicly traded companies, which had all the information necessary to carry out the study in the Economática ${ }^{\circledR}$ database. The period of analysis comprised the years 2006 to 2013. The research is characterized as descriptive, documentary and quantitative. For data analysis, panel data was used through the STATA software. The results indicated that the equity value of the share, the earnings per share and the annual return of the share in the postconvergence period presented an informational increment, showing more alignment with the stock price. In this way, it is inferred that the IFRS added relevance to the accounting information disclosed, contributing to the quality of the accounting information.
\end{abstract}

Keywords: Accounting convergence. IFRS. Brazilian companies. Relevance of information. 


\section{RESUMEN}

Normas internacionales de contabilidad pueden tener aumento de información de los estados financieros, cuando las normas de contabilidad aplicadas previamente, presentando IFRS de menor calidad. La relevancia de la información contable es un rasgo característico de las manifestaciones, que muestra la relación de la información con el precio de las acciones. Por lo tanto, el objetivo de este estudio fue investigar la influencia de la convergencia con las normas internacionales de contabilidad del IASB sobre la relevancia de la información contable divulgada por las empresas brasileñas. La muestra se refiere a 274 empresas listadas, que tenían toda la información para el estudio de la base de datos Economática ${ }^{\circledR}$. El período de revisión era de los años 2006 al 2013. La investigación se caracteriza por ser descriptiva, documento y cuantitativa. Para el análisis de datos se utilizó un panel de datos a través del software STATA. Los resultados indicaron que el valor contable por acción, las ganancias por acción y la declaración anual de la acción en el período posterior a la convergencia presentaron incremento informativo, siendo más alineado con el precio de las acciones. Por lo tanto, parece que el IFRS añadió relevancia para la información contable se describe, contribuye a la calidad de la información contable.

Palabras clave: Convergencia contable. NIIF. Las empresas brasileñas. La información pertinente.

\section{INTRODUÇÃO}

A importância das informações econômico-financeiras para a tomada de decisão tem se acentuado com a internacionalização da economia e dos mercados. As demonstrações contábeis são importante fonte de informações para orientar as decisões de investimento, financiamento e subsidiar previsões dos stakeholders, estejam eles em qualquer parte do mundo. Com isso, a elaboração dessas demonstrações passou a requerer regras uniformes, que possibilitassem aos organismos e investidores internacionais, analisar e interpretar as informações das empresas, levando assim, à convergência às normas internacionais de contabilidade (NIYAMA, 2009).

No Brasil, por meio da Lei no. 11.638/07 e da criação do Comitê de Pronunciamentos Contábeis (CPC), o processo de convergência contábil às normas internacionais foi acelerado. $\mathrm{O}$ CPC foi o órgão responsável em emitir normas nacionais harmonizadas com as normas contábeis internacionais emitidas pelo International Accounting Standards Board (IASB), as chamadas International Financial Reporting Standards (IFRS). Desde então, é relevante analisar a qualidade da informação contábil, com o intuito de investigar se com a adoção de normas contábeis harmonizadas às IFRS, as demonstrações financeiras passaram a ser de melhor qualidade, reportando, de forma transparente, informações aos diversos usuários (PAULO et al., 2013).

No âmbito das mudanças de normas contábeis, de acordo com Macedo, Araújo e Braga (2012), torna-se relevante o conhecimento, por parte de contadores, órgãos reguladores e investidores, do efeito da adoção das IFRS na informação contábil. Investigar se alterações nos critérios de reconhecimento e mensuração de contas contábeis impactaram os relatórios financeiros e, consequentemente, a relevância da informação para o mercado de capitais, é importante na medida em que fornece subsídios sobre os resultados do processo de convergência contábil na busca por melhoria da informação contábil divulgada. 
Neste contexto, o problema de pesquisa está fundamentado na seguinte questão: qual a influência do processo de convergência às normas contábeis internacionais na relevância da informação contábil divulgada por empresas brasileiras? A fim de auxiliar na resolução desta problemática, o objetivo deste estudo é verificar a influência do processo de convergência às normas contábeis internacionais do IASB na relevância da informação contábil divulgada por empresas brasileiras.

Estudos nacionais como os de Lima (2010), Macedo, Machado e Machado (2013), Santos, Starosky Filho e Klann (2014) analisaram, em empresas brasileiras, a relevância da informação contábil após a adoção das IFRS. Lima (2010) investigou a relevância das informações contábeis antes e depois do início do processo de convergência para as normas internacionais de contabilidade no Brasil, compreendendo o período de 1995 a 2009. Macedo, Machado e Machado (2013) compararam a relevância da informação contábil no período pré (anos de 1997 a 2007) e pós (2008 e 2009) do processo de convergência contábil às IFRS, considerando a Lei no. 11.638/07. E, Santos, Starosky Filho e Klann (2014) analisaram a influência do processo de convergência às normas contábeis internacionais no value relevance de informações contábeis de empresas brasileiras, no período de 2006 a 2011.

Em âmbito internacional, Barth, Landsman e Lang (2007) verificaram se a aplicação das Normas Internacionais de Contabilidade estava associada com maior qualidade da informação contábil em empresas de 23 países. Gastón et al. (2010) examinaram o impacto da adoção das IFRS sobre os relatórios financeiros de empresas da Espanha e Reino Unido, e também sobre a relevância da informação contábil. Alfaiate (2012) analisou o impacto da adoção das IFRS na relevância da informação contábil em empresas portuguesas. Tsalavoutas, André e Evans (2012) investigaram, em empresas da Grécia, se a relevância da informação contábil sofreu alteração após a adoção das IFRS. Palea (2014) analisou se as demonstrações financeiras não consolidadas de empresas italianas são úteis para os investidores do mercado de capitais. Também comparou a relevância da informação contábil entre demonstrações com normas IFRS e GAAPs locais.

O presente estudo analisa a lacuna de pesquisa sobre a relevância da informação contábil com a convergência às normas internacionais de contabilidade, considerando o período de análise pré-convergência, os anos de 2006 a 2009, e o período pós-convergência, os anos de 2010 a 2013. Desta forma, diferencia-se dos demais estudos nacionais por investigar um período de análise mais abrangente após a obrigatoriedade de adoção das IFRS em demonstrações consolidadas no Brasil, conforme o recomendado pelo estudo de Santos, Starosky Filho e Klann (2014).

Esta problemática de pesquisa se justifica pela importância que as informações contábeis têm para o desenvolvimento da economia mundial. Além disso, vê-se a necessidade de trazer evidências empíricas à literatura, sobre qual o efetivo reflexo da adoção das normas internacionais para a relevância da informação contábil das companhias, principalmente no Brasil. Martins e Paulo (2010) mencionam que mesmo existindo indícios na literatura de que as divergências existentes entre os padrões contábeis afetem a qualidade das informações financeiras, é ainda vaga a descrição do tipo de impacto que tais divergências acarretam para as informações contábeis utilizadas pelos usuários dessas informações. 


\section{REFERENCIAL TEÓRICO}

Nesta seção são apresentadas as principais referências sobre convergência às normas internacionais de contabilidade e relevância da informação contábil, bem como estudos nacionais e internacionais que embasam a pesquisa.

\subsection{CONVERGÊNCIA ÀS NORMAS INTERNACIONAIS DE CONTABILIDADE}

Com a internacionalização dos mercados, a utilização de práticas contábeis distintas dificultou a comparação das informações econômico-financeiras entre diferentes países, motivando a convergência de normas contábeis em âmbito internacional, principalmente nas empresas com atuação e interesse mundial. Ademais, a diversidade de informações e as diferentes interpretações dos fatos contábeis acarretam a falta de comparabilidade das demonstrações contábeis, ocasionando o descrédito da informação contábil no cenário mundial. Com isso, a convergência às normas internacionais tem gerado mudanças que visam facilitar a análise dos investidores e demais usuários da informação em qualquer parte do mundo, resultando em uma oportunidade para que as empresas possam se tornar competitivas no cenário mundial (ALMEIDA et al., 2008).

Diversos países passaram ou vêm passando pelo processo de convergência de suas normas contábeis para as normas contábeis internacionais. $\mathrm{O}$ processo de convergência às normas internacionais de contabilidade no Brasil iniciou-se com as alterações promovidas pelas Leis $\mathrm{n}^{\mathbf{0}}$. 11.638/07 e nº. 11.941/09, à Lei nº. 6.404/76 (das Sociedades Anônimas).

O Comitê de Pronunciamentos Contábeis (CPC) tem sido o principal elaborador de normas contábeis no Brasil desde a publicação da Lei $\mathrm{n}^{\circ}$. 11.638/07, emitidas em consonância com as normas produzidas pelo IASB. O auge do processo de convergência ocorreu no exercício de 2010, em que as companhias de capital aberto foram obrigadas a adotar as normas internacionais de contabilidade em sua forma completa (nas demonstrações consolidadas) (FREIRE et al., 2012).

Conforme Martins e Paulo (2010) faz-se necessário para as companhias brasileiras que queiram adentrar nos mercados de capitais de outros países, elaborar suas demonstrações financeiras com base nas IFRS. Nesse sentido, pode-se dizer que a convergência às normas internacionais proporciona a melhoria da qualidade das informações contábeis e, por conseguinte, facilita a comunicação entre as companhias e os diferentes usuários de suas informações.

Dimitropoulos et al. (2013) destacam também que as IFRS foram baseadas em princípios orientados ao mercado, com extensa divulgação de informações financeiras das organizações, refletindo a situação econômica e o desempenho empresarial. Com a adoção das IFRS, a qualidade da informação contábil seria aumentada, diminuindo a intervenção de gestores oportunistas na elaboração e divulgações de informações contábeis.

Entretanto, o impacto das IFRS na qualidade da informação contábil, segundo Ahmed, Neel e Wang (2013), é uma questão empírica. O efeito da adoção das IFRS na qualidade da contabilidade depende essencialmente, da qualidade das normas contábeis anteriores aplicadas às empresas, se estas eram de qualidade superior ou inferior às IFRS. Dessa forma, se as IFRS são de melhor qualidade do que as normas contábeis locais, no sentido de reduzir critérios gerenciais sobre escolhas contábeis para a suavização ou exagero de rendimentos, espera-se que sua adoção tenha elevado o nível de qualidade das demonstrações contábeis. Todavia, caso as normas 
contábeis anteriores aplicadas às empresas tivessem melhor qualidade na redução de suavizações de resultados do que as IFRS, então a adoção reduziria a qualidade da informação contábil.

A adoção obrigatória das IFRS fornece evidências de que as demonstrações contábeis de empresas teriam qualidade superior de informações. No entanto, há poucas evidências empíricas sobre esta afirmação, necessitando de maior investigação a fim de se chegar a conclusões sobre o efeito das IFRS na qualidade da informação (HORTON; SERAFEIM; SERAFEIM, 2013).

A relação entre as normas internacionais de contabilidade e a informação financeira de qualidade é controversa no cenário mundial. Defensores das IFRS afirmam que o comportamento oportunista de gestores empresariais tenha sido limitado e que a mensuração e divulgação da situação financeira e econômica das empresas tenham aumentado com a implantação das IFRS em organizações. Os oponentes dessa ideia argumentam que além da adoção das normas internacionais, fatores relacionados às características ambientais do negócio da empresa e quadros institucionais determinam o conteúdo das demonstrações contábeis (CHEN et al., 2010).

As normas internacionais de contabilidade, além da questão relacionada à qualidade da informação contábil, têm gerado maior transparência e comparabilidade das informações, diminuindo assimetrias informacionais. Desta forma, as IFRS podem gerar também impacto nos preços das ações, por fornecer maior transparência informacional sobre o desempenho das empresas (DEVALLE; ONALI; MAGARINI, 2010).

\subsection{RELEVÂNCIA DA INFORMAÇÃO CONTÁBIL}

Órgãos reguladores da contabilidade, tais como o IASB, tem como intuito reduzir e até mesmo extinguir a assimetria da informação contábil em relatórios produzidos pelas empresas (MATOS et al., 2012). A assimetria informacional entre gestores e acionistas pode ser reduzida pela adoção das IFRS, em razão de diminuir o gerenciamento de resultados, reduzir custos de capital, possibilitar previsões de contas de forma correta e aumento da relevância das informações contábeis no preço das ações (LIOU, 2013).

$\mathrm{Na}$ segunda metade do século XX houve um crescimento de pesquisas com enfoque positivista e pautadas na perspectiva de mercado eficiente, em que se investigou a relevância da informação contábil para o mercado de capitais (LOPES; SANT’ANA; COSTA, 2007). De acordo com Ball e Brown (1968), a divulgação de relatórios de contabilidade impacta os preços das ações, principalmente por publicar informações relacionadas ao lucro líquido e patrimônio líquido, que são observados pelos acionistas e investidores. Desta forma, quando os usuários da informação contábil obtêm dados sobre o desempenho de empresas, suas opiniões quanto a estas podem sofrer variação, refletindo nos preços das ações.

$\mathrm{O}$ resultado econômico e financeiro de empresas que profissionais de contabilidade divulgam é importante, visto que reflete diretamente na relevância da informação. A partir do momento em que são publicadas quaisquer informações organizacionais, pode haver variação no preço das ações no mercado, pelo conhecimento dos investidores sobre os resultados das empresas (BEAVER, 1968).

De acordo com Nascimento (2012), a qualidade da informação contábil é bastante discutida atualmente. Um dos motivos é fato dos stakeholders, de uma forma geral, necessitarem de informações relevantes e confiáveis para tomar decisões. A utilidade das demonstrações contábeis está atrelada à relevância das informações divulgadas aos usuários. Essas informações contábeis são consideradas relevantes quando estiverem associadas aos valores de mercado da empresa, se refletir no preço das ações (SILVA; MACEDO; MARQUES, 2012).

Revista Ambiente Contábil - ISSN 2176-9036 - UFRN - Natal-RN. v. 10. n. 1, p. 121 - 138, jan./jun. 2018. 
As informações contábeis possuem conteúdo informativo, capaz de alterar as opiniões e expectativas de investidores, que por sua vez impacta no preço das ações, variando o valor de mercado das empresas. Este poder que as informações contábeis possuem sobre o preço das ações é conhecido como value relevance (LIMA, 2010). Para Barth, Landsman e Lang (2007), se uma informação contábil impactar no preço das ações é porque é relevante para o mercado de capitais. Além disso, a informação contábil deve ser capaz de auxiliar os usuários na avaliação dos efeitos potenciais de transações passadas, presentes e futuras.

A relevância da informação contábil, de acordo com Francis e Schipper (1999), “[...] é verificada pela capacidade de as informações contábeis capturarem ou resumirem informações, independentemente da fonte, que afeta os valores das ações". Para Lopes e Martins (2005), a relevância das informações contábeis é vista por intermédio do impacto da contabilidade nos preços das ações negociadas em mercados de capitais. Por relevante se entende a relação que existe entre a informação contábil e os preços negociados, para ter relevância econômica, os números contábeis devem alterar a percepção da realidade.

$\mathrm{O}$ processo de convergência às normas internacionais de contabilidade, segundo Silva (2013), trouxe maior qualidade às demonstrações financeiras, além de maior tempestividade e relevância das informações. Desta forma, os relatórios contábeis, por serem mais informativos, auxiliam os usuários da contabilidade para a tomada de decisão em relação aos recursos despendidos no mercado de capitais. Quanto maior a qualidade da informação contábil, mais ela deve influenciar o valor das ações e atender às expectativas dos agentes econômicos, sobretudo se forem capazes de transmitir informações sobre os benefícios econômicos futuros que poderão ser obtidos (ALMEIDA, 2010).

\subsection{ESTUDOS RELACIONADOS}

Diversos estudos foram desenvolvidos em âmbito nacional e internacional a fim de investigar a relevância da informação contábil após a adoção das IFRS. Barth, Landsman e Lang (2007) realizaram um estudo com o objetivo de verificar se a aplicação das Normas Internacionais de Contabilidade estava associada com maior qualidade da informação contábil. A amostra foi constituída por 327 empresas de 23 países, a maioria delas da Suíça, China e Alemanha, que adotaram as normas contábeis internacionais entre 1994 e 2003. O período observado compreendeu 1990 a 2003, para que fossem analisados quatro anos antes à adoção das normas. Quanto ao resultado da análise para o período pré e pós-adoção, verificaram que as empresas que adotaram as normas contábeis internacionais apresentaram melhoria na qualidade da informação contábil.

Gastón et al. (2010) examinaram o impacto da adoção das IFRS sobre os relatórios financeiros de empresas da Espanha e Reino Unido. Os resultados da pesquisa apresentaram impacto significativo das IFRS sobre as contas e índices financeiros das empresas dos dois países analisados. Verificaram ainda, que a adoção das IFRS apresentou efeito negativo sobre a relevância da informação contábil em ambos os países, embora esta relação tenha se apresentado significativa apenas em empresas espanholas.

Alfaiate (2012) teve como objetivo analisar o impacto da adoção das IFRS na relevância da informação contábil das empresas portuguesas com valores cotados na Euronext Lisbon, no período de 2002 a 2007. Para isso, analisou a associação entre as variáveis Book Value per Share e Earnings per Share com o valor da cotação das ações de 30 empresas no período antes e após a adoção das IFRS. Como resultado, verificou que o valor relevante do resultado líquido aumentou

Revista Ambiente Contábil - ISSN 2176-9036 - UFRN - Natal-RN. v. 10. n. 1, p. 121 - 138, jan./jun. 2018. 
após a adoção das IFRS, concluindo assim, que a adoção das IFRS teve impacto positivo na relevância da informação contábil das empresas analisadas.

Tsalavoutas, André e Evans (2012) investigaram, em empresas da Grécia, se a relevância da informação contábil do patrimônio líquido e do lucro líquido sofreu alteração após a adoção das IFRS. Com a adoção das IFRS em 2005 pela União Europeia, acreditava-se que as informações contábeis apresentariam maior relevância. Os resultados sugeriram que não houve mudança de relevância da informação contábil entre as contas de patrimônio líquido e lucro líquido. Assim, concluíram que a adoção das IFRS não melhorou a relevância da informação dentre as empresas analisadas.

Palea (2014) investigou se as demonstrações financeiras de empresas italianas não consolidadas são úteis para os investidores do mercado de capitais. Também analisou a relevância da informação contábil entre demonstrações com normas IFRS e GAAPs locais. Os resultados demonstraram que as demonstrações financeiras de acordo com as IFRS não apresentaram incremento de informação relevante, além do que as demonstrações financeiras segundo os GAAPs locais. Ainda, observaram indícios de que as demonstrações financeiras de acordo com os GAAPs locais são mais relevantes em comparação com as que adotaram IFRS.

Com base no exposto, depreende-se que os resultados dos estudos internacionais aqui citados são divergentes, alguns apontando para melhoria da relevância da informação contábil com a adoção das IFRS (BARTH; LANDSMAN; LANG, 2007; ALFAIATE, 2012) e outros indicando efeito nulo ou negativo (GASTÓN et al., 2010; TSALAVOUTAS; ANDRÉ; EVANS, 2012; PALEA, 2014).

No Brasil, Lima (2010) investigou a relevância das informações contábeis antes e depois do início do processo de convergência para as normas internacionais de contabilidade. A amostra utilizada compôs-se de 2.277 observações trimestrais de todas as empresas que compuseram a carteira teórica do Ibovespa durante o período entre 1995 e 2009. Uma das perspectivas analisadas voltou-se para a análise entre a associação de variáveis contábeis (lucro e patrimônio líquido) e variáveis de mercado (preço das ações), a fim de identificar se a adoção de um padrão contábil de maior qualidade no Brasil (IFRS), mesmo em se tratando de uma adoção considerada parcial, aumentava o nível de associação entre essas variáveis. Os resultados indicaram que a relevância da informação contábil, mensurada por meio dos modelos de preço e retorno, aumentou após a adoção parcial das normas IFRS pelas empresas brasileiras.

Macedo, Machado e Machado (2013) analisaram e compararam a relevância da informação contábil no período pré e pós o processo de convergência contábil às IFRS, em empresas brasileiras. O período de análise compreendeu os anos de 1997 a 2009, em que o período pós-convergência foi observado entre os anos 2008 e 2009, considerando a Lei no. 11.638/07. Os principais resultados apontaram que o lucro líquido apresentou ganho da relevância da informação contábil no mercado de capitais no período pós-convergência às IFRS, porém, o patrimônio líquido demonstrou perda de conteúdo informacional no mesmo período.

Santos, Starosky Filho e Klann (2014) verificaram a influência do processo de convergência às normas contábeis internacionais no value relevance de empresas brasileiras, no período de 2006 a 2011. Os resultados demonstraram que o processo de convergência contábil internacional aumentou o poder explicativo do impacto do valor patrimonial da ação e do lucro por ação no preço das ações (seis meses depois de publicadas as informações contábeis).

Portanto, no Brasil, os três estudos apontam para melhoria da relevância da informação contábil após a adoção das IFRS, embora o estudo de Macedo, Machado e Machado (2013) tenha apontado para perda de informação do patrimônio líquido após a convergência.

Revista Ambiente Contábil - ISSN 2176-9036 - UFRN - Natal-RN. v. 10. n. 1, p. 121 - 138, jan./jun. 2018. 


\section{PROCEDIMENTOS METODOLÓGICOS}

Com o intuito de verificar a influência do processo de convergência às normas contábeis internacionais do IASB na relevância da informação contábil divulgada por empresas brasileiras, realizou-se uma pesquisa descritiva, documental e com abordagem quantitativa.

\subsection{POPULAÇÃO E AMOSTRA}

A população do presente estudo compreendeu as empresas de capital aberto, com negociação na Bolsa de Valores, Mercadorias e Futuros de São Paulo (BM\&FBOVESPA). A amostra, por sua vez, refere-se às empresas que dispunham de todas as informações para a realização do estudo, totalizando 274 empresas, no período de análise correspondente aos anos de 2006 a 2013.

\subsection{COLETA E ANÁLISE DOS DADOS}

Os dados para a pesquisa foram coletados na base de dados Economática ${ }^{\circledR}$. Foram coletados os valores para as seguintes variáveis:

Quadro 1 - Variáveis da pesquisa.

\begin{tabular}{|c|c|c|}
\hline Variável & Operacionalização & Fonte \\
\hline $\mathrm{P}_{\mathrm{t} 2+3}$ & $\begin{array}{l}\text { Valor de mercado da ação três meses após o encerramento do } \\
\text { exercício }\end{array}$ & $\begin{array}{l}\text { Lang, Raedy e Yetman (2003) e } \\
\text { Lang, Raedy e Wilson (2006). }\end{array}$ \\
\hline $\mathrm{P}_{\mathrm{t} 2+6}$ & $\begin{array}{l}\text { Valor de mercado da ação seis meses após o encerramento do } \\
\text { exercício. }\end{array}$ & $\begin{array}{l}\text { Lang, Raedy e Yetman (2003) e } \\
\text { Lang, Raedy e Wilson (2006). }\end{array}$ \\
\hline $\mathrm{NI} / \mathrm{P}_{\text {it }}$ & $\begin{array}{l}\text { Refere-se ao lucro por ação divido pelo preço da ação no início } \\
\text { do exercício. }\end{array}$ & Barth, Landsman e Lang (2007). \\
\hline BVEPS $_{\text {it }}$ & Refere-se ao valor patrimonial da ação. & $\begin{array}{l}\text { Lang, Raedy e Yetman (2003) e } \\
\text { Lang, Raedy e Wilson (2006). }\end{array}$ \\
\hline $\mathrm{NIPS}_{\mathrm{it}}$ & Refere-se ao lucro por ação. & $\begin{array}{l}\text { Lang, Raedy e Yetman (2003) e } \\
\text { Lang, Raedy e Wilson (2006). }\end{array}$ \\
\hline RETURN $_{\text {it }}$ & Refere-se ao retorno anual da ação. & Barth, Landsman e Lang (2007). \\
\hline
\end{tabular}

Fonte: Dados da pesquisa.

\subsection{TRATAMENTO E ANÁLISE DOS DADOS}

A primeira medida de value relevance do modelo utilizado por Barth, Landsman e Lang (2007) está baseada no poder explanatório da regressão do preço da ação sobre o lucro líquido e o valor do patrimônio líquido das empresas. Seguindo os estudos de Lang, Raedy e Yetman (2003) e Lang, Raedy e Wilson (2006), fez-se a regressão do valor da ação, três meses após o encerramento do exercício $\left(\mathrm{P}_{\mathrm{t} 2+3}\right)$, com o valor patrimonial da ação (BVEPS) e com o lucro por ação (NIPS), separando a análise em dois períodos: pré-convergência (2006 a 2009) e período pós-convergência (2010 a 2013). A primeira métrica de value relevance consiste no valor do $\mathrm{R}^{2}$ ajustado da regressão dada pela equação 1 :

$$
P_{t 2+3}=\beta_{0}+\beta_{1} B V E P S_{i t}+\beta_{2} N I P S_{i t}+\varepsilon_{i t}
$$

Revista Ambiente Contábil - ISSN 2176-9036 - UFRN - Natal-RN. v. 10. n. 1, p. 121 - 138, jan./jun. 2018. 
Essa primeira medida de value relevance busca analisar se após o processo de convergência às normas contábeis internacionais o valor de mercado da ação está mais alinhado com o valor do patrimônio líquido e do lucro evidenciados pelas empresas. Caso isso ocorra, infere-se que as demonstrações contábeis convergentes com as normas contábeis internacionais refletem melhor a realidade econômica e financeira das empresas, sendo reconhecido pelos investidores do mercado.

Além da equação 1, uma segunda foi utilizada, alterando-se a variável dependente do modelo. Ao invés do preço da ação três meses após o encerramento do exercício $\left(\mathrm{P}_{\mathrm{t} 2+3}\right)$, utilizouse o preço da ação seis meses após o encerramento do exercício $\left(\mathrm{P}_{\mathrm{t} 2+6}\right)$, a fim de comparar o valor do PL e do lucro por ação com o preço de mercado da ação seis meses após o encerramento do exercício.

$$
P_{t 2+6}=\beta_{0}+\beta_{1} B V E P S_{i t}+\beta_{2} N I P S_{i t}+\varepsilon_{i t}
$$

A terceira métrica de value relevance do modelo utilizado por Barth, Landsman e Lang (2007) refere-se ao poder explanatório do lucro líquido por ação (NIPS) sobre o retorno anual da ação (RETURN). Ela é formada pelo valor ajustado do $\mathrm{R}^{2}$ da regressão dada pela equação 3 , que contempla o lucro por ação divido pelo preço da ação no início do exercício (NI/P), como variável dependente, e o logaritmo natural do preço da ação três meses após o fechamento do exercício $\left(\mathrm{P}_{\mathrm{t} 2+3}\right)$, dividido pelo preço da ação no terceiro mês do exercício $\left(\mathrm{P}_{\mathrm{t} 1+3}\right)$ (RETURN), como variável independente:

$$
N I / P_{i t}=\beta_{0}+\beta_{1} R E T U R N+\varepsilon_{i t}
$$

Assim como as equações anteriores, essa medida busca identificar se após o processo de convergência às normas contábeis do IASB, o retorno da ação no mercado está relacionado ao lucro por ação evidenciado pela empresa. Quanto maior essa relação, maior a qualidade da informação contábil divulgada pela empresa. Havendo aumento nessa relação do período préIFRS para o período pós-IFRS, significa que o objetivo da convergência, que é a melhoria da informação divulgada aos usuários, está sendo alcançado.

Os dados não são balanceados em relação ao período analisado, devido à diferenciação das empresas. A análise dos dados foi realizada por meio de regressão de dados em painel, com a utilização do software STATA ${ }^{\circledR}$. Além disso, aplicou-se testes para verificar a aleatoriedade, normalidade e homoscedasticidade entre as variáveis dos dados analisados, por meio do software LHStat $^{\circledR}$.

\section{APRESENTAÇÃO E ANÁLISE DOS RESULTADOS}

Apresenta-se nesta seção, a análise e descrição dos resultados. Primeiramente, aplicaramse os testes de aleatoriedade, normalidade e homoscedasticidade sobre os dados, a fim de verificar o atendimento aos pressupostos da regressão linear múltipla, conforme disposto na Tabela 1. Também foram realizados os testes de Chow, LM de Breusch-Pagan e Hausman para verificar o modelo de análise de dados em painel a ser utilizado. Na sequência, com base nas Tabelas 2 e 3, apresentam-se os resultados da regressão de dados em painel dos modelos 1 a 3, nos quais se separou as observações analisadas, considerando-se o período pré e pós-adoção das normas contábeis internacionais.

Revista Ambiente Contábil - ISSN 2176-9036 - UFRN - Natal-RN. v. 10. n. 1, p. 121 - 138, jan./jun. 2018. 
$\mathrm{Na}$ Tabela 1 podem-se visualizar os testes de aleatoriedade, normalidade e homoscedasticidade de cada modelo analisado.

Tabela 1 - Testes de aleatoriedade, normalidade e homoscedasticidade

\begin{tabular}{|c|c|c|}
\hline Pressupostos & $\begin{array}{c}\text { Testes } \\
\end{array}$ & Hipóteses \\
\hline \multirow{6}{*}{ 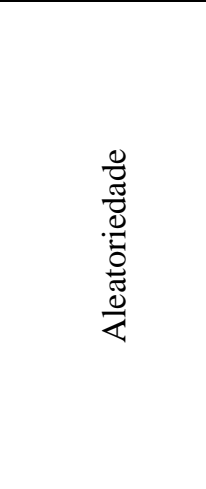 } & $\begin{array}{l}\text { (1 pré) Durbin-Watson. Estatística } \mathrm{DW}=1,9914 \\
\text { Valor-p }=0,8550 ; \text { Autocorrelação dos resíduos }=0,0043\end{array}$ & \multirow{6}{*}{$\begin{array}{l}\text { Inexiste autocorrelação } \\
\text { de primeira ordem entre } \\
\text { os resíduos. }\end{array}$} \\
\hline & $\begin{array}{l}\text { (2 pré) Durbin-Watson: Estatística } \mathrm{DW}=1,8437 \\
\text { Valor-p }=0,0503 ; \text { Autocorrelação dos resíduos }=0,0782\end{array}$ & \\
\hline & $\begin{array}{l}\text { (3 pré) Durbin-Watson: Estatística } \mathrm{DW}=2,0051 \\
\text { Valor-p }=0,9628 ; \text { Autocorrelação dos resíduos }=-0,0025\end{array}$ & \\
\hline & $\begin{array}{l}\text { (1 pós) Durbin-Watson. Estatística DW =2,0127 } \\
\text { Valor-p = 0,9169; Autocorrelação dos resíduos }=0,0064\end{array}$ & \\
\hline & $\begin{array}{l}\text { (2 pós) Durbin-Watson: Estatística } \mathrm{DW}=2,0329 \\
\text { Valor-p }=0,7008 ; \text { Autocorrelação dos resíduos }=-0,0164\end{array}$ & \\
\hline & $\begin{array}{l}\text { (3 pós) Durbin-Watson: } \text { Estatística } \mathrm{DW}=1,9844 \\
\text { Valor-p }=0,8161 ; \text { Autocorrelação dos resíduos }=0,0078\end{array}$ & \\
\hline \multirow{6}{*}{ 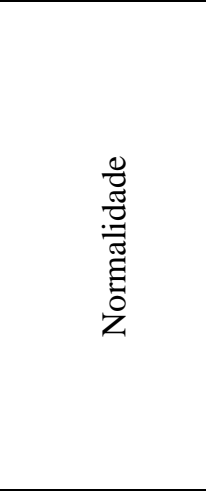 } & $\begin{array}{l}\text { (1 pré) Shapiro-Wilk: } \\
\text { Estatística } S W=0,3259 ; \text { Valor-p }=0,0000\end{array}$ & \multirow{6}{*}{$\begin{array}{l}\text { A distribuição dos } \\
\text { resíduos é normal. }\end{array}$} \\
\hline & $\begin{array}{l}\text { (2 pré) Shapiro-Wilk: } \\
\text { Estatística } S W=0,7707 ; \text { Valor-p }=0,0000\end{array}$ & \\
\hline & $\begin{array}{l}\text { (3 pré) Shapiro-Wilk: } \\
\text { Estatística } S W=0,1169 ; \text { Valor-p }=0,0000\end{array}$ & \\
\hline & $\begin{array}{l}\text { (1 pós) Shapiro-Wilk: } \\
\text { Estatística SW }=0,5959 ; \text { Valor-p }=0,0000\end{array}$ & \\
\hline & $\begin{array}{l}\text { (2 pós) Shapiro-Wilk: } \\
\text { Estatística SW }=0,5007 ; \text { Valor-p }=0,0000\end{array}$ & \\
\hline & $\begin{array}{l}\text { (3 pós) Shapiro-Wilk: } \\
\text { Estatística } S W=0,2656 ; \text { Valor-p }=0,0000\end{array}$ & \\
\hline \multirow{6}{*}{ 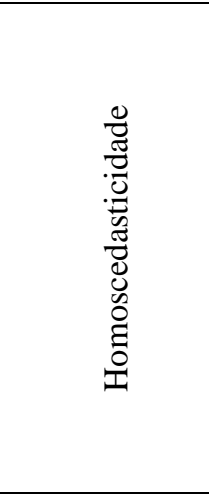 } & $\begin{array}{l}\text { (1 pré) Levene: } \\
\text { Estatística } \mathrm{F}=5,6745 ; \text { Valor-p }=0,0175\end{array}$ & \multirow{6}{*}{$\begin{array}{l}\text { A variância dos erros é } \\
\text { uniforme. }\end{array}$} \\
\hline & $\begin{array}{l}\text { (2 pré) Levene: } \\
\text { Estatística } \mathrm{F}=19,9799 ; \text { Valor-p }=0,0000\end{array}$ & \\
\hline & $\begin{array}{l}\text { (3 pré) Levene: } \\
\text { Estatística } \mathrm{F}=5,0017 ; \text { Valor-p }=0,0257\end{array}$ & \\
\hline & $\begin{array}{l}\text { (1 pós) Levene: } \\
\text { Estatística } F=0,4696 ; \text { Valor-p }=0,4934\end{array}$ & \\
\hline & $\begin{array}{l}\text { (2 pós) Levene: } \\
\text { Estatística } \mathrm{F}=0,0791 ; \text { Valor-p }=0,7786\end{array}$ & \\
\hline & $\begin{array}{l}\text { (3 pós) Levene: } \\
\text { Estatística } F=1,2309 ; \text { Valor-p }=0,2676\end{array}$ & \\
\hline
\end{tabular}

Fonte: Dados da pesquisa.

Com base na Tabela 1, verifica-se que os modelos 1 ao 3, período pré e pós-convergência às normas internacionais de contabilidade não apresentaram problemas de aleatoriedade, normalidade e homoscedasticidade. O teste de Durbin-Watson (DW) nos modelos analisados apresentou-se próximo ao valor 2, conforme recomendado por Marôco (2003), demonstrando a inexistência de autocorrelação entre os resíduos, portanto, atendeu ao pressuposto da aleatoriedade.

Por meio do teste Shapiro-Wilk (SW), que verifica a "distribuição de frequência acumulada de um conjunto de valores observados da amostra com uma distribuição esperada ou teórica" (FÁVERO et al. 2009, p. 112), observou-se que a distribuição dos resíduos é normal. O

Revista Ambiente Contábil - ISSN 2176-9036 - UFRN - Natal-RN. v. 10. n. 1, p. 121 - 138, jan./jun. 2018. 
teste de Levene $(\mathrm{F})$, ao verificar a homoscedasticidade dos dados, demonstrou uniformidade na variância dos erros, referente aos dados analisados.

A Tabela 2 apresenta os dados em painel dos modelos 1,2 e 3, relativos ao período préconvergência.

Tabela 2 - Dados em painel - modelos 1 ao 3 (período pré-convergência)

\begin{tabular}{|c|c|c|c|c|c|c|}
\hline \multirow[t]{2}{*}{ Variáveis } & \multicolumn{2}{|c|}{$\begin{array}{c}\text { Modelo } 1 \text { - } \mathbf{P}_{\mathbf{t} 2+3} \\
\text { Efeito fixo }\end{array}$} & \multicolumn{2}{|c|}{$\begin{array}{l}\text { Modelo } 2 \text { - Pt2+6 } \\
\text { Efeito aleatório }\end{array}$} & \multicolumn{2}{|c|}{$\begin{array}{l}\text { Modelo } 3-\mathrm{Ni} / \mathrm{P}_{\text {it }} \\
\text { Efeito aleatório }\end{array}$} \\
\hline & Coeficientes & VIF & Coeficientes & VIF & Coeficientes & VIF \\
\hline Constante & $-12,26628 *$ & - & $13,91731^{*}$ & - & $-7,392928$ & - \\
\hline BVEPS $_{\text {it }}$ & $3,606285^{*}$ & 1,021 & $0,711575^{*}$ & 1,021 & - & - \\
\hline NIPS $_{\text {it }}$ & $0,611512^{* * *}$ & 1,021 & 0,030577 & 1,021 & - & - \\
\hline RETURN $_{\text {it }}$ & - & - & - & - & $-16,77973$ & 1,000 \\
\hline $\mathrm{R}^{2}$ & \multicolumn{2}{|c|}{0,5126} & \multicolumn{2}{|c|}{0,3169} & \multicolumn{2}{|c|}{0,0020} \\
\hline Sig. & \multicolumn{2}{|c|}{0,0000} & \multicolumn{2}{|c|}{0,0000} & \multicolumn{2}{|c|}{0,1081} \\
\hline Chow & \multicolumn{2}{|c|}{$\begin{array}{c}2,59 \\
(0,0000) \\
\end{array}$} & \multicolumn{2}{|c|}{$\begin{array}{c}2,90 \\
(0,0000)\end{array}$} & \multicolumn{2}{|c|}{$\begin{array}{c}34,23 \\
(0,0000)\end{array}$} \\
\hline LM de Breusch-Pagan & \multicolumn{2}{|c|}{$\begin{array}{c}6,89 \\
(0,0043)\end{array}$} & \multicolumn{2}{|c|}{$\begin{array}{c}103.28 \\
(0,0000)\end{array}$} & \multicolumn{2}{|c|}{$\begin{array}{c}35,02 \\
(0,0000)\end{array}$} \\
\hline Hausman & \multicolumn{2}{|c|}{$\begin{array}{c}196,69 \\
(0,0000)\end{array}$} & \multicolumn{2}{|c|}{$\begin{array}{c}1,35 \\
(0,5083)\end{array}$} & \multicolumn{2}{|c|}{$\begin{array}{c}1,82 \\
(0,1769)\end{array}$} \\
\hline
\end{tabular}

* significativo a $1 \%, * *$ significativo a $5 \%, * * *$ significativo a $10 \%$.

Fonte: Dados da pesquisa.

O teste de Chow apresenta como hipótese nula a utilização do efeito fixo, rejeitando o modelo POLS. O teste de LM de Breusch-Pagan rejeita ou não a possibilidade de utilização do modelo POLS, caso haja rejeição, indica-se a utilização do efeito aleatório. O teste de Hausmam apresenta a rejeição ou não da hipótese nula, caso haja rejeição, utiliza-se o efeito fixo, caso contrário, recomenda-se o efeito aleatório (FÁ VERO et al. 2009).

No modelo 1 os testes de Chow, LM de Breusch-Pagan e Hausman foram significativos a $5 \%$, desse modo, aplicou-se o efeito fixo. Nos modelos 2 e 3, os testes de Chow e LM de Breusch-Pagan demonstraram-se significativos a 5\%, porém, o teste de Hausmam demonstrou-se não significativo, favorecendo a aplicação do efeito aleatório nos modelos.

Os modelos 1 e 2 pré-convergência apresentaram-se significativos a $1 \%$, enquanto o modelo 3 não apresentou significância. $O$ poder de explicação do modelo 1 (preço da ação três meses depois de publicadas as informações) demonstrou-se maior $(0,5126)$ em comparação ao modelo 2 (0,3169).

Em relação à significância das variáveis, observou-se que o valor patrimonial da ação (BVEPS) apresentou influência significativa e positiva no valor de mercado da ação, tanto no modelo que considera o preço da ação três meses $\left(\mathrm{P}_{\mathrm{t}+3}\right)$ depois de publicadas as demonstrações contábeis, como no modelo de seis meses $\left(\mathrm{P}_{\mathrm{t}+6}\right)$. O lucro por ação (NIPS) apresentou efeito significativo e positivo no valor de mercado da ação, mas apenas quando considerado o preço da ação três meses $\left(\mathrm{P}_{\mathrm{t}+3}\right)$ após o encerramento do exercício. Infere-se a partir destes resultados que o BVEPS possui influência mais duradoura do que o NIPS, pois mantém sua influência sobre o preço da ação mesmo após seis meses do encerramento do exercício, enquanto o NIPS perde tal influência a partir deste período.

Na Tabela 3 apresentam-se os dados em painel dos modelos 1, 2 e 3, considerando o período pós-convergência.

Revista Ambiente Contábil - ISSN 2176-9036 - UFRN - Natal-RN. v. 10. n. 1, p. 121 - 138, jan./jun. 2018. 
Tabela 3 - Dados em painel - modelos 1 ao 3 (período pós-convergência)

\begin{tabular}{|c|c|c|c|c|c|c|}
\hline \multirow[t]{2}{*}{ Variáveis } & \multicolumn{2}{|c|}{$\begin{array}{l}\text { Modelo } 1 \text { - } \mathbf{P}_{12+3} \\
\text { Efeito fixo }\end{array}$} & \multicolumn{2}{|c|}{$\begin{array}{l}\text { Modelo } 2 \text { - } \mathbf{P}_{t_{2+6}} \\
\text { Efeito aleatório }\end{array}$} & \multicolumn{2}{|c|}{$\begin{array}{c}\text { Modelo } 3-\mathrm{Ni} / \mathrm{P}_{\text {it }} \\
\text { POLS } \\
\end{array}$} \\
\hline & Coeficientes & VIF & Coeficientes & VIF & Coeficientes & VIF \\
\hline Constante & $9,874501 *$ & - & $17,53747 *$ & - & 0,3020983 & - \\
\hline BVEPS $_{\text {it }}$ & $0,973824 *$ & 1,013 & $0,057956^{*}$ & 1,013 & - & - \\
\hline NIPS $_{\text {it }}$ & 0,0664994 & 1,013 & $0,182553 * *$ & 1,013 & - & - \\
\hline RETURN $_{\text {it }}$ & - & - & - & - & $3,084701^{*}$ & 1,000 \\
\hline $\mathrm{R}^{2}$ & \multicolumn{2}{|c|}{0,8428} & \multicolumn{2}{|c|}{0,1422} & \multicolumn{2}{|c|}{0,1280} \\
\hline Sig. & \multicolumn{2}{|c|}{0,0000} & \multicolumn{2}{|c|}{0,0002} & \multicolumn{2}{|c|}{0,0000} \\
\hline Chow & \multicolumn{2}{|c|}{$\begin{array}{c}14,06 \\
(0,0000)\end{array}$} & \multicolumn{2}{|c|}{$\begin{array}{c}24,43 \\
(0,0000)\end{array}$} & \multicolumn{2}{|c|}{$\begin{array}{c}1,47 \\
(0,0002) \\
\end{array}$} \\
\hline LM de Breusch-Pagan & \multicolumn{2}{|c|}{$\begin{array}{c}397,56 \\
(0,0000)\end{array}$} & \multicolumn{2}{|c|}{$\begin{array}{c}429,43 \\
(0,0000)\end{array}$} & \multicolumn{2}{|c|}{$\begin{array}{c}2,12 \\
(0,0729)\end{array}$} \\
\hline Hausman & \multicolumn{2}{|c|}{$\begin{array}{c}45,47 \\
(0,0000)\end{array}$} & \multicolumn{2}{|c|}{$-162,95$} & \multicolumn{2}{|c|}{$\begin{array}{c}0,40 \\
(0,5287)\end{array}$} \\
\hline
\end{tabular}

* significativo a $1 \%, * *$ significativo a $5 \%$, *** significativo a $10 \%$.

Fonte: Dados da pesquisa.

Conforme a Tabela 3, aplicou-se o efeito fixo ao modelo 1 pós-convergência, devido à significância dos testes de Chow, LM de Breusch-Pagan e Hausman. Os testes Chow e LM de Breusch-Pagan, no modelo 2, apresentaram-se significantes, entretanto, o teste de Hausman não se demonstrou conclusivo (-162,95). Desse modo, aplicou-se o efeito aleatório, ao considerar que no modelo 2 do período pré-convergência foi aplicado o efeito aleatório. Para o modelo 3 aplicou-se o POLS, pois os testes de LM de Breusch-Pagan e Hausman não foram significativos.

Em relação à significância dos modelos 1, 2 e 3 pós-convergência, observou-se que todos foram estatisticamente significativos a $1 \%$. Quanto ao poder explicativo, constatou-se que as variáveis testadas apresentam maior poder de explicação no preço da ação três meses após o exercício $\left(\mathrm{P}_{\mathrm{t}+3}\right)$, com 84,28\%, seguida pelo preço da ação de seis meses após o exercício $\left(\mathrm{P}_{\mathrm{t}+6}\right)$, com 14,22\% e, por fim, o lucro líquido por ação (NI/P), com 12,80\%.

$\mathrm{O}$ valor patrimonial da ação (BVEPS) demonstrou-se significativo e com efeito positivo no valor de mercado da ação três meses $\left(\mathrm{P}_{\mathrm{t}+3}\right)$ e seis meses $\left(\mathrm{P}_{\mathrm{t}+6}\right)$ após o encerramento do exercício. O lucro por ação (NIPS) influenciou significativa e positivamente o valor de mercado da ação de seis meses $\left(\mathrm{P}_{\mathrm{t}+6}\right)$ após o encerramento do exercício. O retorno anual da ação (RETURN), ao contrário do modelo 3 no período pré-convergência, demonstrou efeito significativo e positivo no lucro líquido por ação (NI/P).

Ao comparar esses resultados com os encontrados do período pré-convergência, observou-se uma alteração no comportamento da variável NIPS, que apresentou influência significativa sobre o preço da ação, mas apenas seis meses após o encerramento do exercício, enquanto no período pré-convergência tal influência foi constatada apenas quando utilizado o preço da ação três meses após o fechamento do período. Portanto, após a convergência notou-se um alongamento do efeito no NIPS sobre o preço das ações, de três para seis meses.

Ainda comparando os resultados entre os períodos pré e pós-convergência, constatou-se uma elevação no $\mathrm{R}^{2}$ do modelo 1 , de $51 \%$ no período pré para $84 \%$ no período pós-convergência. Assim, denota-se que as informações contábeis ganharam poder informacional no período pósconvergência contábil, impactando principalmente no preço das ações três meses depois de divulgadas as demonstrações financeiras. Já no modelo 2 o período pré-convergência apresentou maior $\mathrm{R}^{2}(32 \%)$ em relação ao período pós-convergência (14\%), o que pode representar que após

Revista Ambiente Contábil - ISSN 2176-9036 - UFRN - Natal-RN. v. 10. n. 1, p. 121 - 138, jan./jun. 2018. 
a adoção das IFRS as informações contábeis refletem mais rapidamente no mercado, o que foi constatado no modelo 1.Observou-se também que somente no período pós-convergência contábil o retorno anual da ação apresentou-se com poder informacional para impactar o lucro líquido por ação.

Deste modo, infere-se que as IFRS agregaram relevância às informações divulgadas, resultando em maior alinhamento entre as variações nos valores contábeis do patrimônio líquido e lucro líquido com as alterações nos preços das ações.

Estes achados corroboram os estudos internacionais de Barth, Landsman e Lang (2007) e Alfaiate (2012), que constataram que as IFRS impactaram positivamente a relevância informacional contábil, em diversas empresas da Europa. No entanto, os resultados obtidos vão de encontro aos achados de Gastón et al. (2010), Tsalavoutas, André e Evans (2012) e Palea (2014), os quais verificaram que as IFRS tiveram impacto negativo na relevância da informação contábil ou não apresentaram incremento informacional em comparação aos GAAPs locais, em empresas analisadas da Espanha, Reino Unido, da Grécia e da Itália.

Os estudos nacionais de Lima (2010), Macedo, Machado e Machado (2013), Santos, Starosky Filho e Klann (2014) obtiveram resultados divergentes. Lima (2010), Santos, Starosky Filho e Klann (2014) verificaram incremento informacional pela adoção das IFRS nas empresas brasileiras analisadas. Entretanto, Macedo, Machado e Machado (2013) evidenciaram que o lucro líquido apresentou incremento informacional pela adoção das IFRS, enquanto o patrimônio líquido demonstrou perda informacional.

Os resultados encontrados no presente estudo corroboram os achados de estudos nacionais (LIMA, 2010; SANTOS; STAROSKY FILHO; KLANN, 2014), por evidenciar que a convergência contábil às IFRS impactou no aumento da relevância da informação contábil em empresas brasileiras. A contribuição desses achados ocorre na medida em que se considerou um período pós-convergência mais abrangente do que as pesquisas anteriores.

Os resultados também estão em congruência com os resultados verificados por Santos, Starosky Filho e Klann (2014), sobre a relevância do patrimônio e lucro por ação no período pós convergência, entretanto, observaram que no período pós convergência (2010 e 2011) as informações possuíam maior relevância no preço das ações seis meses depois de publicadas as informações e no atual estudo, que compreendeu período maior de análise no período pós convergência (2010 a 2013) o poder maior de explicação do impacto das variáveis contábeis foi no preço das ações três meses depois de publicadas as informações. Desta forma, infere-se que com a análise de período maior no período pós-convergência, constatou-se que as informações contábeis perdem relevância de valor ao longo do tempo.

\section{CONSIDERAÇÕES FINAIS}

O presente estudo teve por objetivo verificar a influência do processo de convergência às normas contábeis internacionais do IASB na relevância da informação contábil divulgada por empresas brasileiras. A metodologia utilizada foi descritiva, documental e quantitativa. A População compreendeu as empresas listadas na BM\&FBOVESPA e amostra final foi composta por 274 empresas que dispunham de todos os dados para a realização do estudo. O período de análise correspondeu aos anos de 2006 a 2013.

Para verificar a influência da adoção das IFRS na relevância informacional, foram distribuídas as observações dos anos analisados em duas categorias, o período pré-convergência, que correspondeu aos anos de 2006 a 2009, e o período pós-convergência, de 2010 a 2013. Como

Revista Ambiente Contábil - ISSN 2176-9036 - UFRN - Natal-RN. v. 10. n. 1, p. 121 - 138, jan./jun. 2018. 
técnica estatística usou-se de regressão de dados em painel não balanceados, por meio do software STATA.

Os resultados demonstraram que o valor patrimonial da ação teve impacto significativo e positivo no valor de mercado da ação, tanto três quanto seis meses após o encerramento do exercício. A variável lucro por ação apresentou efeito significativo e positivo no valor de mercado das ações três meses após o encerramento do exercício no período pré-convergência, e seis meses após o encerramento do exercício no período pós-convergência. Também se observou que no período pós-convergência o retorno anual da ação apresentou efeito positivo no lucro líquido por ação. Desse modo, constatou-se que no período pós-convergência as variáveis testadas ganharam poder informacional.

Em relação ao poder explicativo dos modelos, verificou-se que as variáveis perderam poder explicativo com o passar do tempo, ao considerar que o $\mathrm{R}^{2}$ dos modelos com preço da ação de três meses foi maior do que os modelos de seis meses. Além disso, constatou-se uma elevação do poder explicativo do modelo 1 do período pré para o período pós-convergência. Assim, denota-se que as informações contábeis ganharam poder informacional no período pósconvergência contábil, impactando principalmente no preço das ações três meses depois de divulgadas as demonstrações financeiras. Somado a isto, no modelo 2, que considera o preço da ação seis meses após o encerramento do exercício, o período pré-convergência apresentou maior poder explicativo. Infere-se, desta forma, que após a adoção das IFRS as informações contábeis podem refletir mais rapidamente no mercado, concentrando sua influência nos três meses após o encerramento do exercício e, por conta disso, apresentando menor influência no modelo de preço de seis meses.

Dadas estas constatações, em relação à principal temática investigada, verificou-se que a adoção das IFRS pelas empresas analisadas contribuiu com a relevância da informação contábil, ou seja, colaborou com o aumento da qualidade informacional da contabilidade, ao se comparar com os GAAPs nacionais utilizados anteriormente. Conclui-se, assim, que a adoção das IFRS, quanto à relevância da informação contábil, apresentou-se mais informativa aos usuários da contabilidade em relação às normas nacionais, o que pode impactar positivamente na qualidade da tomada de decisão de investidores quanto aos recursos dispendidos no mercado de capitais.

Sugere-se como pesquisas futuras, a utilização de outros modelos de qualidade da informação contábil, como gerenciamento de resultado, conservadorismo, tempestividade, suavização, entre os demais modelos abordados na literatura. Recomenda-se ainda, a utilização da amostra analisada, a fim de detectar o efeito da convergência contábil às IFRS na qualidade da informação contábil de empresas brasileiras, em relação a diversas medidas de qualidade.

\section{REFERÊNCIAS}

AHMED, A. S.; NEEL, M.; WANG, D. Does mandatory adoption of IFRS improve accounting quality? Preliminary evidence. Contemporary Accounting Research, v. 30, n. 4, p. 1344-1372, 2013.

ALFAIATE, L. I. N. O impacto das IFRS na relevância da informação contabilística. 2012, f. 43. Dissertação (Mestrado em Contabilidade, Fiscalidade e Finanças Empresariais), Instituto Superior de Economia e Gestão, Universidade Técnica de Lisboa, Lisboa, 2012. 
ALMEIDA, J. E. F. Qualidade da informação contábil em ambientes competitivos. São Paulo, 2010. Tese (Doutorado em Ciências Contábeis) - Programa de Pós-Graduação em Ciências Contábeis, Departamento de Contabilidade e Atuária, Faculdade de Economia, Administração e Contabilidade, Universidade de São Paulo. 2010.

ALMEIDA, M. D.; LEMES, S; WEFFORT, E. F. J.; MALAQUIAS, R. F. Análise da percepção sobre expressões de incerteza presentes nas normas internacionais de contabilidade. Revista UnB Contábil, v. 11, n. 1-2, p. 240-259, 2008.

BALL, R.; BROWN, P. An empirical evaluation of accounting income numbers. Journal of accounting research, p. 159-178, 1968.

BARTH, M. E.; LANDSMAN, W. R.; LANG, M. H. International accounting standards and accounting quality. Journal of accounting research, v. 46, n. 3, p. 467-498, 2007.

BEAVER, W. H. The information content of annual earnings announcements. Journal of accounting research, p. 67-92, 1968.

BRASIL. Lei $\mathrm{n}^{\circ} 11.638$ de 28 de Dezembro de 2007. Altera a Lei n6.404/76 das Sociedades por Ações. Diário Oficial [da] República Federativa do Brasil, Brasília, DF, 28 dez. 2007.

CHEN, H.; TANG, Q.; JIANG, Y.; LIN, Z.. The role of international financial reporting standards in accounting quality: Evidence from the European Union. Journal of International Financial Management \& Accounting, v. 21, n. 3, p. 220-278, 2010.

DEVALLE, A.; ONALI, E.; MAGARINI, R. Assessing the value relevance of accounting data after the introduction of IFRS in Europe. Journal of international financial management \& accounting, v. 21, n. 2, p. 85-119, 2010.

DIMITROPOUlOS, P. E., ASTERIOU, D., KOUSENIDIS, D., LEVENTIS, S. The impact of IFRS on accounting quality: Evidence from Greece. Advances in Accounting, 2013.

FÁVERO, L. P.; BELFIORE, P.; SILVA, F. L.; CHAN, B. L. Análise de Dados: Modelagem Multivariada para tomada de decisões. Rio de Janeiro: Elsevier, 2009.

FRANCIS, J.; SCHIPPER, K. Have financial statement lost their relevance? Journal of Accounting Research, v. 37, n. 2, p. 319-352, 1999.

FREIRE, M. D. M.; MACHADO, M. R. R.; MACHADO, L. S.; SOUZA, E. S.; OLIVEIRA, J. J. Aderência às normas internacionais de contabilidade pelas empresas brasileiras. RCO - Revista de Contabilidade e Organizações, v. 6, n. 15, p. 3-22, 2012.

GASTÓN, S. C.; GARCÍA, C. F.; JARNE, J. I. J.; GADEA, J. A. L. IFRS adoption in Spain and the United Kingdom: Effects on accounting numbers and relevance. Advances in Accounting, v. 26, n. 2, p. 304-313, 2010. 
HORTON, J.; SERAFEIM, G.; SERAFEIM, I. Does Mandatory IFRS Adoption Improve the Information Environment?*. Contemporary Accounting Research, v. 30, n. 1, p. 388-423, 2013.

LANG, M.; RAEDY, J. S.; WILSON, W. Earnings management and cross listing: Are reconciled earnings comparable to US earnings? Journal of Accounting and Economics, v. 42, n. 1, p. 255-283, 2006.

LANG, M.; RAEDY, J. S.; YETMAN, M. H. How representative are firms that are cross-listed in the united states? An analysis of accounting quality. Journal of Accounting Research, v. 41, n. 2, p. 363-386, 2003.

LIMA, J. B. N. A relevância da informação contábil e o processo de convergência para as normas IFRS no Brasil. Tese (doutorado em Ciências Contábeis) Departamento de Contabilidade e Atuária da Faculdade de Economia, Administração e Contabilidade, Universidade de São Paulo, 2010.

LIOU, C. H. A Study on Financial Reporting Standards and Accounting Quality-Evidence from China. In: Journal of Physics: Conference Series. IOP Publishing, 2013.

LOPES, A. B.; MARTINS, E. Teoria da Contabilidade: uma nova abordagem. São Paulo: Atlas, 2005.

LOPES, A. B.; SANT'ANNA, D; COSTA, F. M. A relevância das informações contábeis na Bovespa a partir do arcabouço teórico de Ohlson: avaliação dos modelos de Residual Income Valuation e Abnormal Earnings Growth. Revista de Administração da Universidade de São Paulo, v. 42, n. 4, 2007.

MACEDO, M. A. S.; ARAÚJO, M. B. V.; BRAGA, J. P. Impacto do processo de convergência às normas internacionais de contabilidade na relevância das informações contábeis. Revista de Educação e Pesquisa em Contabilidade (REPeC), v. 6, n. 4, 2012.

MACEDO, M. A. S.; MACHADO, M. A. V.; MACHADO, M. R. Análise da relevância da informação contábil no Brasil num contexto de convergência às normas internacionais de contabilidade. Revista Universo Contábil, v. 9, n. 1, p. 65-85, 2013.

MARÔCO, J. Análise Estatística com utilização do SPSS. $2^{a}$ ed. Lisboa: Sílabo, 2003.

MARTINS, O. S.; PAULO, E. O reflexo da adoção das IFRS na análise de desempenho das companhias de capital aberto no brasil. RCO - Revista de Contabilidade e Organizações, v. 4, n. 9, p. 30-54, 2010.

MATOS, E. B. S. D.; NIYAMA, J. K.; FERNANDES, J. L. T.; BOTELHO, D. R. Um estudo sobre a pesquisa em educação contábil em periódicos internacionais: temáticas envolvendo as normas internacionais de contabilidade. 2012. Revista Contexto, v. 12, n. 22, p. 59-73, 2012.

NASCIMENTO, A. S. Adoção do IFRS no Brasil: Uma análise dos efeitos na comparabilidade e na relevância das demonstrações contábeis. Dissertação (Mestrado em

Revista Ambiente Contábil - ISSN 2176-9036 - UFRN - Natal-RN. v. 10. n. 1, p. 121 - 138, jan./jun. 2018. 
Ciências Contábeis) - Programa de Mestrado em Ciências Contábeis da Universidade do Estado do Rio de Janeiro. 2012.

NIYAMA, J. K. Comparação entre princípios contábeis norte-americanos e brasileiros principais divergências no âmbito das instituições financeiras. Contabilidade, Gestão e Governança, v. 1, n. 1, 2009.

PALEA, V. Are IFRS value-relevant for separate financial statements? Evidence from the Italian stock market. Journal of International Accounting, Auditing and Taxation, v. 23, n. 1, p. 117, 2014.

PAULO, E.; GIRÃO, L. F. D. A. P.; CARTER, D.; SOUZA, R. S. The Impact of the Adoption of International Financial Reporting Standards on the Quality of Accounting Information of the Brazilian and European Public Firms. Available at SSRN 2270678, 2013.

SANTOS, A. C.; STAROSKY FILHO, L.; KLANN, R. C. Efeitos do processo de convergência às normas internacionais de contabilidade no value relevance das demonstrações contábeis de organizações brasileiras. Revista Contemporânea de Contabilidade, v. 11, n. 22, p. 95-118, 2014.

SILVA, A. F.; MACEDO, M. A. S.; MARQUES, J. A. V. C. Análise da Relevância da Informação Contábil no Setor Brasileiro de Energia Elétrica no período de 2005 a 2007: uma discussão com foco nas variáveis LL, FCO e EBITDA. Revista Universo Contábil, v. 8, n. 2, p. 06-24, 2012.

SILVA, R. L. M. Adoção completa das IFRS no Brasil: qualidade das demonstrações contábeis e o custo de capital próprio. Tese (Doutor em Ciências Contábeis) Departamento de Contabilidade e Atuária da Faculdade de Economia, Administração e Contabilidade da Universidade de São Paulo, 2013.

TSALAVOUTAS, I.; ANDRÉ, P.; EVANS, L. The transition to IFRS and the value relevance of financial statements in Greece. The British Accounting Review, v. 44, n. 4, p. 262-277, 2012. 